\title{
Florence Nightingale e as suas contribuições para o controle das infecções hospitalares*
}

\section{Florence Nightingale and its contributions to the control of hospital acquired infections}

Dayane Franco Martins ${ }^{1}$ Linconl Agudo Oliveira Benito ${ }^{2}$
Recebido em: 10/12/2015.

Aprovado em: 26/09/2016.

1 Graduanda em Enfermagem do Centro Universitário de Brasília (UniCEUB).

2 Docente do Centro Universitário de Brasília (UniCEUB).

\section{Resumo}

Tratou-se de uma revisão sistemática de literatura e que analisou as contribuições de Florence Nightingale contra a infecção hospitalar. Para desenvolvimento deste estudo, foi eleito um universo de 27 publicações, adquiridas juntamente às bases de dados BVS, SABER-USP, e PUBMED. Por meio do presente estudo, foram percebidas as contribuições de Florence Nightingale no combate e controle aos processos de infecção hospitalar, influenciando, inclusive, na administração e arquitetura hospitalar, em âmbito internacional, sendo reconhecida por profissionais de saúde e de outras áreas do conhecimento. Essa revisão permitiu identificar a importância do impacto da Teoria Ambientalista, por meio da atenção concedida ao paciente em diversas ações, as quais foram incorporadas na enfermagem mesmo ainda em uma era pré-bacteriológica.

Palavras-chave: Enfermagem. Infecção. Hospital. Assistência sanitária. Epidemiologia.

\begin{abstract}
This was a systematic review of the literature and analyzed the contribution of Florence Nightingale against hospital infection. To develop this study, he was elected a universe of 27 publications, acquired from the VHL databases, SABER-USP, and PUBMED. Through this study were perceived contributions from Florence Nightingale to combat and control the hospital infection cases, including influencing the administration and hospital architecture, internationally and is recognized by health professionals and other areas of knowledge. This review has identified the importance of the impact of Environmentalist Theory, through the attention given to the patient in several actions, in which were incorporated in nursing even still in age pre-bacteriological.
\end{abstract} Keywords: Nursing. Infection. Hospital. Health assistance. Epidemiology. 


\section{Introdução}

Indiscutivelmente, Florence Nightingale é motivo e exemplo de inspiração, além de objeto de pesquisa para vários estudiosos em todo o mundo. Em sua época, Nightingale contribuiu, significativamente, para a melhoria e para o desenvolvimento da saúde hospitalar, mantendo-se, até a atualidade, enquanto pessoa que em muito contribuiu para as várias áreas do conhecimento, mesmo após mais de 100 anos de seu falecimento (GAROFALO, 2010).

Florence Nightingale é considerada a fundadora da enfermagem moderna, segundo algumas notas escritas pela própria Nightingale em suas cartas, no qual podemos conhecê-la um pouco nos trechos a seguir.

Florence Nightingale (1820-1910) nasceu em Florença (Itália). Sua maior realização foi o estabelecimento do conceito da preparação formal para a prática de enfermagem, formada em matemática, porém sua maior devoção foi na profissão de enfermagem, após sentir que Deus a tinha dado um chamado. Mesmo contrariando sua família, ela cumpriu sua promessa de cuidar dos doentes. Sua fama logo se espalhou que pouco tempo depois foi convidada a conhecer a rainha Vitória, que a admirou por sua devoção ao salvar milhares de soldados na Guerra da Crimeia [...] (NIGHTINGALE, 1989, p. 53-54).

Segundo Oguisso (2005), Nightingale provocou uma revolução no conceito de enfermeira da época, proclamando uma identidade profissional singular e simbiótica em termos de rituais e simbologia, disciplina e poder. A administração de hospitais, a formação da enfermeira e a educação em serviço, a preservação do ambiente, controle de infecções, dados epidemiológicos, sanitarismo, eram algumas das suas maiores preocupações.

A visão de Nightingale objetivava priorizar o fornecimento de um ambiente estimulador do desenvolvimento da saúde para o paciente. Ela acreditava que isso faria um diferencial na recuperação dos doentes, e são esses preceitos que sustentam a Teoria Ambientalista. Nightingale passou a adotar conceitos que definem o que envolve a questão do ambiente, sendo esses, vistos como componentes físico, social e psicológico, os quais precisam ser entendidos como inter-relacionados, e não partes distintas separadas (GEORGE, 2000).

A preocupação de Nightingale com ambiente hospitalar e meio ambiente já em 1863 enfatizava a co- modidade do paciente com as condições locais, como por exemplo, a iluminação, a limpeza, o sanitarismo, a ventilação, a temperatura, a atenção, o cuidado, os odores e os ruídos. Em seu intenso cuidado, ela priorizava o isolamento, uma dieta adequada, a individualização do cuidado, a redução do número de leitos por enfermaria, evitando dessa forma contaminações cruzadas e a diminuição da circulação de pessoas fora do serviço em âmbito hospitalar, evitando, dessa forma, condições desfavoráveis aos pacientes (NIGHTINGALE, 1989).

Segundo Padilha (1998) a história de Nightingale tem provido de ensinamento para toda a humanidade, especialmente para a enfermagem. Seu altruísmo e propósito em modificar as condições e formas como eram atribuídas à saúde e condições sanitárias da sociedade no final do século XIX, que deixaram marcas significativas à história.

As Infecções Relacionadas à Assistência à Saúde (IRAS) se constituem enquanto componentes essenciais para a democratização e para o aprimoramento da gestão em serviços de saúde. Com a missão de proteger e promover a saúde da população, a Agência Nacional de Vigilância Sanitária (ANVISA) é responsável por definir as normas gerais, os critérios e os métodos para a prevenção e controle das IRAS no Brasil (ANVISA, 2013).

Considerando as determinações do Ministério da Saúde (MS) da Lei no 9.431 de 6 de janeiro de 1997 na Portaria No 2616, de 12 de maio de 1998 do MS (BRASIL, 1998), que dispõe sobre a obrigatoriedade da manutenção pelos hospitais do país, de Programa de Controle de Infecções Hospitalares (PCIH). Sendo assim, podemos dizer que as infecções Hospitalares constituem risco significativo à saúde dos usuários dos hospitais, e sua prevenção e controle envolvem medidas de qualificação de assistência hospitalar, da vigilância sanitária e outras, tomadas no âmbito do Estado, do Município e de cada hospital, atinentes a seu funcionamento (BRASIL, 1998).

Sendo que a Infecção hospitalar (IH) é aquela adquirida após a admissão do paciente e que se manifeste durante a internação ou após a alta, quando puder ser relacionada com a internação ou procedimentos hospitalares. Na assistência à saúde, independentemente de ser prevenção, proteção ou tratamento e reabilitação, o indivíduo deve ser visto como um ser integral, que não se fragmenta para receber atendimento em partes. As IH são multifatoriais e toda a problemática de como redu- 
zir as infecções, intervir em situações de surtos e manter sob controle as infecções dentro de uma instituição deve ser resultado de um trabalho de equipe (PEREIRA et al., 2005).

Mesmo diante do valor comprovado da higienização ou lavagem das mãos ou outros simples gestos na prevenção da transmissão microbiana, profissionais de saúde, continuam ignorando esse gesto simples e parece não compreenderem os mecanismos básicos da transmissão das doenças infecciosas (HESELTINE, 2001). O princípio fundamental do legado de Nightingale para a prática da profissão é a questão do ambiente. Os ideais referentes a esse princípio foram fundamentados na Teoria Ambientalista e foram considerados primordiais para o sucesso do trabalho de Nightingale, sendo verificados na eficaz redução das mortes de soldados feridos por infecção e na recuperação de pacientes.

Nesse sentido, se constituiu enquanto objetivo do presente estudo, apresentar as principais contribuições de Florence Nightingale para o combate as infecções hospitalares, relacionadas ao sanitarismo e epidemiologia.

\section{Metodologia}

Trata-se de um estudo de revisão sistemática (RS) da literatura qualitativa que é adequado para buscar consenso sobre alguma temática específica e sintetizar o conhecimento de uma dada área por meio da formulação de uma pergunta, identificação, seleção e avaliação crítica de estudos científicos contidos em bases de dados eletrônicas. A partir desse processo, ela permite, além de aprofundar o conhecimento sobre a temática investigada, apontar lacunas que precisam ser preenchidas por meio da realização de novas investigações (LOPES; FRACOLLI, 2008).

Baseado nos estudos de Hearst (2003) os procedimentos metodológicos utilizados no processo desta revisão sistemática incluíram: (a) formulação da questão de pesquisa; (b) identificação dos estudos concluídos; (c) definição de critérios de inclusão e exclusão; (d) extração uniforme de características e resultados de cada estudo; (e) apresentação clara e uniforme dos resultados.

A análise ocorreu com base em um quadro com a apresentação dos estudos selecionados para a sumarização dos pontos principais expostos nos artigos. Essa tabela serviu de base para nortear as características metodológicas e a discussão. Para a elaboração das referências, foram utilizadas enquanto metodologia a pesquisa bibliográfica e pesquisa exploratória descritiva.

Foram utilizados para essa revisão livros, artigos de periódicos e teses, em que foram coletados nas bases de dados Scientific Eletronic Library Online (SciELO), Portal de Teses da USP, BIREME e Literatura Latino-Americana e do Caribe em ciências da Saúde (LILACS), disponíveis online em texto completo. Os seguintes descritores da Biblioteca Virtual em Saúde (BVS) foram aplicados "Enfermagem" número do registro 3183 e identificador único D003152, "Infecção" número do registro 895 e identificador único D000881, "Hospital" número do registro 289 e identificador único D000289, "Assistência sanitária" número do registro 3709e identificador único D003695 e "Epidemiologia" número do registro 22080 e identificador único Q000453. Para tal, foram considerados os seguintes critérios de inclusão para a seleção das referências: pesquisas originais, reflexões e revisões de literatura, teses e dissertações disponíveis online gratuitamente no formato completo, nas línguas "portuguesa", "inglesa" e "espanhola", que apresentassem, em seus títulos e/ou resumos, as palavras: Florence Nightingale, totalizando 808 referências, pertencente ao recorte histórico formado pelos anos de "1989" a "2016", totalizando vinte e seis (26) anos.

Porém, para que atendessem os critérios de exclusão das referências supracitadas, primeiramente, foi realizada a leitura do título e/ou resumo, no qual foram desconsideradas todas as produções duplicadas. Em seguida foram excluídas todas as referências que não atendiam aos requisitos constituídos para este estudo, sendo eles, estudos que englobasse em seu resumo, as palavras "Florence Nightingale", "Hospital", "Enfermagem", "Epidemiologia", "Infecção Hospitalar" e/ou "sanitarismo", sendo identificado um universo de 808 referências e restando apenas 38 referências para análise detalhada, a qual ocorreu mediante leitura criteriosa do texto, se verificando a aderência e a pertinência ao escopo do estudo.

O processo de revisão das referências foi desenvolvido por um pesquisador e supervisionado por outro, permitindo desta forma um melhor processamento e escolha das referências a serem utilizadas na edificação da presente pesquisa.

A amostra final foi composta apenas por 27 referências, incluindo apenas as de maior relevância para este estudo, que apresentassem um embasamento científico que contribuísse significativamente para o desenvolvi- 
mento deste artigo. Os dados foram organizados em um quadro expositivo, com a identificação dos estudos com base em sua referência e as principais observações dos autores, de acordo com a proposta deste trabalho. O total de trabalhos excluídos está demonstrado na Figura 1. Em seguida será apresentada a tabela 1, onde foi demonstrada a quantidade de trabalhos produzidos em cada ano respectivamente.

Figura 1 - Fluxograma das referências selecionadas.

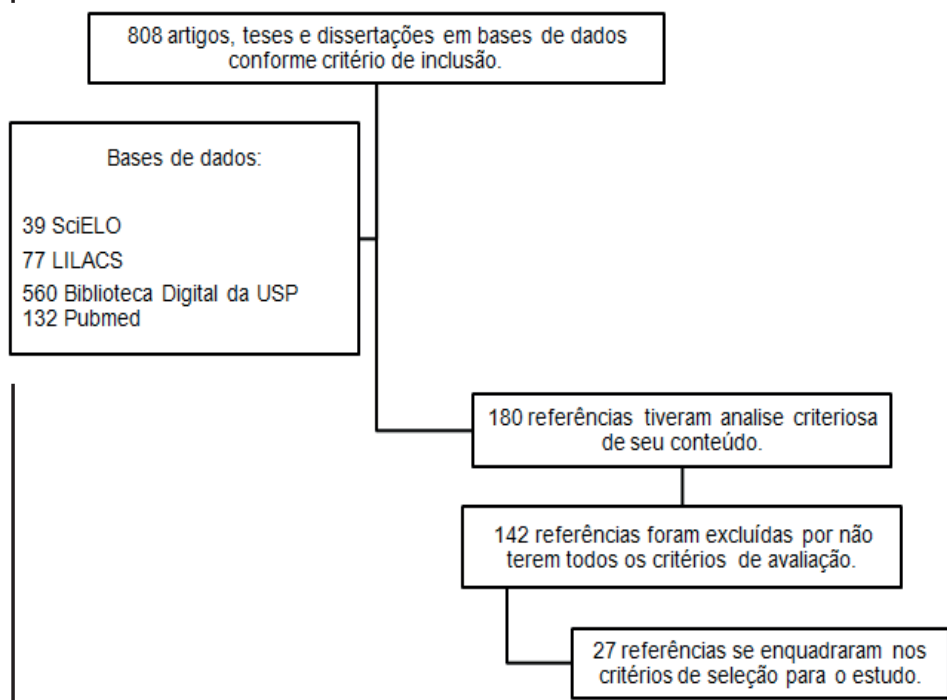

Fonte: Produção dos autores.

Tabela 1 - Frequência de publicações utilizadas no desenvolvimento do presente estudo, por ano e percentual $(n=27)$ :

\begin{tabular}{lcc}
\hline Ano & Frequência & $\%$ \\
\hline 1994 & 1 & 3,70 \\
\hline 1999 & 1 & 3,70 \\
\hline 2002 & 1 & 3,70 \\
\hline 2005 & 1 & 3,70 \\
\hline 2008 & 4 & 14,80 \\
\hline 2009 & 2 & 7,40 \\
\hline 2011 & 4 & 18,55 \\
\hline 2012 & 3 & 11,10 \\
\hline 2013 & 8 & 100 \\
\hline 2014 & 2 & 7,40 \\
\hline T0TAL & 27 & \\
\hline Fon & 1 & \\
\hline
\end{tabular}

\section{Resultados}

Em toda coleta na base de dados nesta pesquisa sistemática, foram localizados 180 estudos dentre eles artigos científicos, dissertações e teses, sendo selecionados apenas 27, no qual se enquadraram nos critérios preestabelecidos, sendo 05 de produções internacionais e 22 publicações nacionais.

Os estudos a serem apresentados, após o uso dos critérios de elegibilidade, envolveram a relação de Florence Nightingale com as práticas de saúde atuais de ante a sua influência por meio de sua teoria ambientalista e as demais práticas que deram uma nova concepção a saúde pública e ao ambiente hospitalar, mostrando que mesmo em uma era pré-bacteriana, Nightingale não desprezou a importância dos cuidados frente às infecções relacionadas à assistência à saúde, e como conquistou o título de pioneira na vigilância sanitária e epidemiologia.

Nesse sentido, cabe destacar que o papel revolucionário na saúde, no qual sem a dedicação e atenção da precursora Nightingale não haveria cuidado ou mesmo a sistematização da assistência de enfermagem, capaz de evitar tais agravantes como as infecções hospitalares, porém, nos dias atuais, nos encontramos em uma era de escassez onde esqueceram a importância do cuidado e das precauções, onde de fato ainda ocorrem diversas contaminações cruzadas, como podemos observar nos surtos de superbactérias.

Para facilitar a análise e apresentação dos resultados, elaborou-se o Quadro 1 com a apresentação dos estudos selecionados para análise, contendo autor e ano em ordem cronológica, título da publicação, tipo de trabalho e principais observações dos autores. Os estudos analisados foram publicados entre os anos de 1994 a 2014. Segue as seis (06) áreas de contribuições relevantes apresentadas em destaque no estudo, localizadas nos trabalhos. 
Quadro 1 - Apresentação dos estudos selecionados para análise correspondente a tópicos importantes nas percepções dos autores sobre as contribuições de Florence Nightingale expressas em cada referência selecionada.

\begin{tabular}{|c|c|c|c|}
\hline Autor/Ano & Título da publicação & Tipo de trabalho & Principais observações dos autores \\
\hline FERNANDES, 2014 & $\begin{array}{l}\text { Acreditação Hospitalar: A percepção da equi- } \\
\text { pe de enfermagem do Centro Cirúrgico de um } \\
\text { Hospital Universitário }\end{array}$ & $\begin{array}{l}\text { Dissertação de Mestrado } \\
\text { em Enfermagem }\end{array}$ & $\begin{array}{l}\text { FN introduziu a responsabilidade da enfermagem de buscar por ambiente hospitalar } \\
\text { biologicamente seguro e confortável, livre de infecçôes hospitalares. }\end{array}$ \\
\hline JACKSON, 2014 & $\begin{array}{l}\text { Infection prevention as "'I a show": A quali- } \\
\text { tative study of nurses' infection prevention } \\
\text { behaviors. }\end{array}$ & Artigo original & $\begin{array}{l}\text { Ressalta que o legado de FN permanece forte na atualidade e como a sua influência } \\
\text { aparece abundantemente nos enfermeiros da atualidade e na reforma social e de saú } \\
\text { de, incluindo saneamento, higiene, design hospitalar e as estatísticas. }\end{array}$ \\
\hline BARBAN, 2013 & $\begin{array}{l}\text { Análise da mobilização e resultados do trans- } \\
\text { plante hematopoiéticas autogênico (TCTHa) } \\
\text { com alta hospitalar precoce nos portadores } \\
\text { de doenças hematológicas }\end{array}$ & $\begin{array}{l}\text { Dissertação de Mestrado } \\
\text { em Medicina }\end{array}$ & $\begin{array}{l}\text { FN influenciou na reforma sanitária da índia, nas melhores práticas de saúde do povo } \\
\text { indígena da Austrália, nos avanços no controle da infecção e epidemiologia hospitalar } \\
\text { As práticas relativas à infecção, até os dias atuais ainda são aplicáveis no cuidado ac } \\
\text { paciente. }\end{array}$ \\
\hline CARRAR0, 2013 & $\begin{array}{l}\text { Contribuições de Florence Nightingale: uma } \\
\text { revisão Integrativa da literatura }\end{array}$ & Artigo original & $\begin{array}{l}\text { FN tornou clara as relações entre o ser humano, } 0 \text { ambiente e a natureza como um } \\
\text { meio de aprendizagem para crescimento profissional por meio da conexão entre saú } \\
\text { de, cuidado e cura. Ressalta que antes da atuação de } \mathrm{FN} \text { os hospitais eram como casa } \\
\text { de repouso, onde a morte coexistia desveladamente com a vida; insetos e roedore } \\
\text { disputavam alimento com os pacientes; mortos e vivos permaneciam no mesmo leito }\end{array}$ \\
\hline FRELL0, 2013 & $\begin{array}{l}\text { Las contribuciones de Florence Nightingale: } \\
\text { una revisión integradora de la literatura }\end{array}$ & Artigo original & $\begin{array}{l}\text { Descreve a influência de FN em diversas áreas além da enfermagem, a exemplo da } \\
\text { estatística, administração em saúde, saúde pública, fisioterapia e espiritualidade. }\end{array}$ \\
\hline C. JUNIOR, 2013 & $\begin{array}{l}\text { Análise do ensino de genética e genômica } \\
\text { em cursos de graduação em enfermagem } \\
\text { no Brasil }\end{array}$ & $\begin{array}{l}\text { Dissertação de Mestrado de } \\
\text { Enfermagem }\end{array}$ & $\begin{array}{l}\text { FN promoveu mudanças marcantes como a higiene básica e as medidas estritas para } \\
\text { a diminuição da propagação de organismos infecciosos, junto a análises epidemio } \\
\text { lógicas das causas das mortes, onde proporcionaram evidências científicas da enfer- } \\
\text { magem que refletiram um aspecto diferenciado do cuidado/atenção com qualidade. }\end{array}$ \\
\hline MATARAZZO, 2013 & $\begin{array}{l}\text { Composições cromáticas no ambiente hospi- } \\
\text { talar: estudo de novas abordagens }\end{array}$ & $\begin{array}{l}\text { Dissertação de Mestrado } \\
\text { em Arquitetura e } \\
\text { Urbanismo. }\end{array}$ & $\begin{array}{l}\text { Nightingale escreveu a importância a respeito das vantagens da recuperação do } \\
\text { efeitos imediatos da cirurgia em uma unidade separada do hospital, observando sel } \\
\text { cuidado de evitar infecçôes cruzadas vindas de outros pacientes enfermos e um cui- } \\
\text { dado melhor assistido. }\end{array}$ \\
\hline ROSSANEIS, 2013 & $\begin{array}{l}\text { Indicadores de qualidade adotados nos ser- } \\
\text { viços de enfermagem de hospitais de ensino } \\
\text { do estado do Paraná, Brasil }\end{array}$ & $\begin{array}{l}\text { Dissertação de Mestrado } \\
\text { em Enfermagem }\end{array}$ & $\begin{array}{l}\text { As contribuições da enfermeira inglesa Florence Nightingale ampliaram os conhecimento } \\
\text { etornarampossivelneutralizaradoreprotegercontraasinfecçôescontraídasnoatocirúrgico }\end{array}$ \\
\hline FELIX, 2013 & $\begin{array}{l}\text { Fatores individuais, laborais e organiza- } \\
\text { cionais à adesão às precauções-padrão de } \\
\text { profissionais de enfermagem em uma insti- } \\
\text { tuição privada }\end{array}$ & $\begin{array}{l}\text { Tese de doutorado de } \\
\text { Enfermagem }\end{array}$ & $\begin{array}{l}\text { Destaca-se a atuação de FN a desenvolver a prática com suporte epidemiológico para } \\
\text { a prevenção e controle de doenças infecciosas, numa época pré-bacteriológica e re- } \\
\text { forçando a ideia de que FN é considerada a pioneira na aplicação da estatística e da } \\
\text { epidemiologia. }\end{array}$ \\
\hline VALLE, 2013 & $\begin{array}{l}\text { Competências do enfermeiro para ações pre- } \\
\text { ventivas na atenção domiciliar com ênfase } \\
\text { nos riscos de infecção }\end{array}$ & $\begin{array}{l}\text { Tese de Doutorado de } \\
\text { Enfermagem }\end{array}$ & $\begin{array}{l}\text { Nightingale teve sua significativa importância histórica com a reorganização dos hos } \\
\text { pitais e a implantação de medidas sanitárias, práticas básicas de higiene, isolamento } \\
\text { dos enfermos, atendimento individual, e a redução de leitos no mesmo ambiente } \\
\text { medidas essas que colaboraram para a redução das taxas de mortalidade hospitalaa } \\
\text { daquela época. }\end{array}$ \\
\hline FERREIRA, 2012 & $\begin{array}{l}\text { Adoção da Sistematização de Assistência de } \\
\text { Enfermagem em Unidades de Referência em } \\
\text { Hanseníase no Município de São Paulo: limi- } \\
\text { tes e possibilidades }\end{array}$ & $\begin{array}{l}\text { Dissertação de mestrado } \\
\text { em enfermagem }\end{array}$ & $\begin{array}{l}\text { FN instituiu o modelo ambiental de saúde que ainda hoje é preconizado pelo Minis- } \\
\text { tério da Saúde. }\end{array}$ \\
\hline MORAES, 2012 & $\begin{array}{l}\text { As contribuições do atendimento educacio- } \\
\text { nal em ambiente hospitalar a crianças que } \\
\text { realizam tratamento oncológico }\end{array}$ & $\begin{array}{l}\text { Tese de Doutorado de } \\
\text { medicina }\end{array}$ & FN é considerada uma das precursoras da epidemiologia hospitalar. \\
\hline SCARPARO, 2012 & $\begin{array}{l}\text { Perspectivas do gerenciamento de enferma- } \\
\text { gem hospitalar Perspectivas do gerencia- } \\
\text { mento de enfermagem hospitalar }\end{array}$ & $\begin{array}{l}\text { Tese de Doutorado de } \\
\text { Enfermagem }\end{array}$ & $\begin{array}{l}\text { FN colocou em atuação o que considerava serem as práticas ideais para a enferma- } \\
\text { gem, preocupando-se com a alimentação adequada, a limpeza, a ventilação do am- } \\
\text { biente, a higiene, a separaçãa entre os doentes e os feridos. }\end{array}$ \\
\hline
\end{tabular}




\begin{tabular}{|c|c|c|c|}
\hline CARRASC0, 2011 & $\begin{array}{l}\text { Comprensión de la enfermería desde la pers- } \\
\text { pectiva Histórica de Florencia Nightingale }\end{array}$ & Artigo original & $\begin{array}{l}\text { Apesar da forte resistência por parte dos militares e médicos, FN conseguiu organizar, } \\
\text { e avaliar estatisticamente o impacto da atenção sobre os soldados doentes durante a } \\
\text { guerra, causadas principalmente por doenças infecciosas. Depois de um ano de tra- } \\
\text { balho FN conseguiu reduzir as taxas de mortalidade dos feridos na Guerra da Criméia } \\
\text { de } 40 \% \text { para } 2 \% \text { em apenas seis meses, onde registrava suas observações e utilizou } \\
\text { tais registros/anotações para posterior avaliação e implantação de padrões sanitários. }\end{array}$ \\
\hline COSTA, 2011 & $\begin{array}{l}\text { Aplicação do Pediatric Risk of Mortality es- } \\
\text { core (PRISM) e determinação dos fatores de } \\
\text { prognóstico para óbito em uma unidade de } \\
\text { terapia intensiva pediátrica terciária }\end{array}$ & $\begin{array}{l}\text { Dissertação de Mestrado } \\
\text { em Medicina }\end{array}$ & $\begin{array}{l}\text { Sustentada na teoria ambientalista de } \mathrm{FN} \text { a autora nos diz ela vai além do ambiente } \\
\text { físico ao preocupar-se com a qualidade do cuidado realizado ao ser humano, apontan- } \\
\text { do suas necessidades como: distrações a partir de estímulos visuais, visitas agradáveis, } \\
\text { contatos com a natureza, trabalhos manuais, dentre outros. }\end{array}$ \\
\hline $\begin{array}{l}\text { HADDAD e SANTOS, } \\
2011\end{array}$ & $\begin{array}{l}\text { A teoria ambientalista de Florence Nightin- } \\
\text { gale no ensino da escola de enfermagem } \\
\text { Anna Nery (1962 - 1968) }\end{array}$ & Artigo original & $\begin{array}{l}\text { Sustenta a importância de uma das principais teorias (Teoria Ambientalista) de enfer- } \\
\text { magem e sua correlação com o ensino da prática da profissão. }\end{array}$ \\
\hline JARDIM, 2011 & $\begin{array}{l}\text { Avaliação das práticas de prevenção e contro- } \\
\text { le da infecção da corrente sanguínea associa- } \\
\text { da ao cateter venoso central de curta perma- } \\
\text { nência por meio de indicadores clínicos }\end{array}$ & $\begin{array}{l}\text { Dissertação de Mestrado } \\
\text { em Ciências }\end{array}$ & $\begin{array}{l}\text { FN colocou a enfermagem no patamar de ciência ao utilizar os recursos de limpeza, } \\
\text { isolamento, individualização do cuidado, deita adequada, diminuição de leitos por } \\
\text { enfermaria, diminuiç̧ão de pessoas estranha ao serviço, como forma de reduzir os } \\
\text { efeitos negativos e de contaminação no meio hospitalar. Sendo importante registrar } \\
\text { que a enfermagem assume as funções de prevenção e controle da contaminação do } \\
\text { ambiente hospitalar, através deste trabalho de FN. }\end{array}$ \\
\hline SAVAGE, et al., 2009 & $\begin{array}{l}\text { Public Health and Nursing: A Natural Parte- } \\
\text { ship }\end{array}$ & Artigo Original & $\begin{array}{l}\text { FN, uma pioneira reconhecida em epidemiologia, prevenção e ciência da saúde públi- } \\
\text { ca e gestão do ambiente para o controle de infecções. Ela também avançou a ciência } \\
\text { da saúde pública por meio de seu trabalho em saneamento básico, vigilância e sua } \\
\text { dedicação à reforma social. Tudo isso após elucidar sobre as péssimas condições rela- } \\
\text { cionadas com os cuidados de saúde disponível para os pobres doentes, bem como a } \\
\text { sua vida e condições de trabalho. }\end{array}$ \\
\hline WIN KELSTEIN, 2009 & $\begin{array}{l}\text { Florence Nightingale: founder of modern } \\
\text { nursing and hospital epidemiology }\end{array}$ & Artigo original & $\begin{array}{l}\text { Na ilustre galeria dos que desenvolveram conhecimentos e métodos que contribuíram } \\
\text { para controle da infecção hospitalar estão FN, Joseph Lister, Louis Pasteur e William } \\
\text { Halstedt. }\end{array}$ \\
\hline FIGUEIRED0, 2008 & Gestão do projeto de edifícios hospitalares & $\begin{array}{l}\text { Dissertação de Mestrado } \\
\text { em Arquitetura. }\end{array}$ & $\begin{array}{l}\text { FN desenvolveu métodos de coletas de dados que objetivaram a melhoria da qualida- } \\
\text { de do atendimento prestado aos feridos. FN utilizou-se de indicadores (por exemplo, } \\
\text { taxa de mortalidade), para provar que por meio do controle sanitário, as mortes po- } \\
\text { deriam diminuir. }\end{array}$ \\
\hline FONSECA, 2008 & $\begin{array}{l}\text { Revisão integrativa da pesquisa em enferma- } \\
\text { gem em centro cirúrgico no Brasil: trinta anos } \\
\text { após o SAEP }\end{array}$ & $\begin{array}{l}\text { Dissertação de mestrado } \\
\text { em enfermagem }\end{array}$ & $\begin{array}{l}\text { Desde os primórdios, a enfermagem em centro cirúrgico era responsável pelo ambien- } \\
\text { te seguro, confortável e limpo para a realizaçãa da operação. Essa importância foi sa- } \\
\text { lientada por FN que preconizou as boas condiçōes ambientais como fator importante } \\
\text { para o restabelecimento da saúde. }\end{array}$ \\
\hline OLALDE, 2008 & $\begin{array}{l}\text { Escala SERVQUAL: validação para a cultura } \\
\text { mexicana e a qualidade de serviço de enfer- } \\
\text { magem, segundo a percepção de pacientes } \\
\text { hospitalizados }\end{array}$ & $\begin{array}{l}\text { Tese de doutorado em } \\
\text { Enfermagem }\end{array}$ & $\begin{array}{l}\text { Florence implantou rígidos padrões sanitários que reduziu a taxa de mortalidade sig- } \\
\text { nificativamente estabelecendo um dos primeiros modelos de melhoria da qualidade } \\
\text { em saúde. }\end{array}$ \\
\hline PENHA 2008 & $\begin{array}{l}\text { A expressão da dimensão espiritual no cuida- } \\
\text { dos de enfermagem em UTI }\end{array}$ & $\begin{array}{l}\text { Dissertação de mestrado } \\
\text { em enfermagem }\end{array}$ & $\begin{array}{l}\text { As péssimas condições de higiene, os inúmeros casos de cólera e tifo impulsionam } \\
\text { FN a solicitar uma Comissão Sanitária ao governo Britânico. Após a intervenção da } \\
\text { referida comissão, as taxas e mortalidade caíram abruptamente. }\end{array}$ \\
\hline GILL, 2005 & $\begin{array}{l}\text { Nightingale in Scutari: Her Legacy Reexa- } \\
\text { mined }\end{array}$ & Artigo original & $\begin{array}{l}\text { Já em 1860, FN enfatizou a importância da higiene, limpeza e padrões de cuidados e } \\
\text { sanitarismo, a fim de evitar as infecções hospitalares, porém mesmo com todos esses } \\
\text { anos ainda se encontra infecções em hospitais e outros serviços de saúde, no qual } \\
\text { permeiam uma grande preocupação para os serviços de saúde. }\end{array}$ \\
\hline ANDRADE, 2002 & $\begin{array}{l}\text { Infecção hospitalar: mitos, e verdades, velhos } \\
\text { hábitos, novas atitudes }\end{array}$ & Artigo original & $\begin{array}{l}\text { Refere que nos escritos de FN, resgata a importância na prevenção de infecç̃oes em } \\
\text { campo cirúrgico, por meio de seus suportes epidemiológicos onde FN aplicava as me- } \\
\text { didas de prevenção da proliferação e transmissão de microrganismos. Além disto, ela } \\
\text { se preocupava em conhecer as doenças e medidas de prevenção de infecçōes. }\end{array}$ \\
\hline
\end{tabular}




\begin{tabular}{|c|l|c|l|}
\hline PADILHA, 1999 & $\begin{array}{l}\text { As representações da história da enferma- } \\
\text { gem na prática cotidiana atual }\end{array}$ & Artigo original & $\begin{array}{l}\text { FN influenciou diretamente em sua passagem nos locais onde se executava o cuidado } \\
\text { de enfermagem leigo e fundamentados nos conceitos religiosos de caridade, amor ao } \\
\text { próximo, doação, humildade e também pelos preceitos de valorização do ambiente } \\
\text { adequado para o cuidado, divisão social do trabalho em enfermagem e autoridade } \\
\text { sobre o cuidado a ser prestado ao paciente. }\end{array}$ \\
\hline CARRAR0, 1995 & $\begin{array}{l}\text { Resgatando Florence Nightingale: a trajetó- } \\
\text { ria da enfermagem junto ao ser humano e } \\
\text { sua família na prevenção de infecções }\end{array}$ & $\begin{array}{l}\text { Dissertação de Mestrado de } \\
\text { Enfermagem }\end{array}$ & $\begin{array}{l}\text { FN permaneceu em Scutari por 21 meses, organizou, limpou, humanizou. Reduziu } \\
\text { de 42\% para 2\% a mortalidade entre os feridos de guerra Virou Lenda, como Dama } \\
\text { da Lamparina, mas também como sanitarista e administradora. Durante sua atuação } \\
\text { Florence se dedicouà reforma do saneamento do exército, aos hospitais do exérrito, ao } \\
\text { saneamento da Índia e entre as classes mais pobres da Inglaterra. }\end{array}$ \\
\hline
\end{tabular}

Legenda: FN - (Florence Nightingale).

Fonte: Produção dos autores.

Ao longo dos estudos selecionados por esta revisão, foram possíveis identificarpontos marcantes em destaques na enfermagem, por meio de Nightingale, como os cuidados no centro cirúrgico, terapia intensiva, triagem, ambiente hospitalar, arquitetura hospitalar, administração e política, em que, por meio de suas insistentes lutas na política, para uma saúde melhor, puderam, significativamente, ocorrer melhoras no âmbito hospitalar como forma de prevenção a possíveis contaminações cruzadas. Estas desencadearam graves riscos de infecção hospitalar. Observou-se, por meio de diversos estudos, a importância da precursora da enfermagem em várias áreas da saúde e como as suas influências modificaram a saúde em todo o mundo (ELLIS, 2010).

Ao observar o resultado desta análise, dentre os 11 anos nos quais foram encontrados os trabalhos referentes ao tema de pesquisa, pode-se perceber que houve uma grande elevação na quantidade de trabalhos com esta temática. Mostrando-nos mais uma vez, a seriedade e relevância deste estudo. Em destaque o ano de 2013, onde houve um elevado número de trabalhos sobre Florence Nightingale, por marcarem as comemorações pelo ano internacional da Enfermeira e o centenário de falecimento de Florence Nightingale, resgatando pelos autores sua extrema importância para o cenário hospitalar.

Para facilitar a discussão do presente trabalho os estudos selecionados no quadro 1 foram categorizados, conforme o foco principal do estudo (quadro 2), ao qual será dado destaque na discussão dos resultados.

Quadro 2 - Categorização das referências selecionadas

\begin{tabular}{|c|c|}
\hline Ambiente & Pacientes (Triagem) \\
\hline Epidemiologia & Política (Administração) \\
\hline Centro Cirúrgico & Sanitarismo \\
\hline
\end{tabular}

\section{Discussão}

As pesquisas revelaram a importância de lembrarmos como é almejar alguma coisa comque tanto nos importamos, como é o caso de Nightingale, que, mesmo sem tecnologia, foi possível nos mostrar que não há ganho sem trabalho e nos garantiu que houvesse modificações revolucionárias na saúde, e o crédito que a enfermagem ao idealizar a Teoria de Ambientalista, afirmando que o indivíduo cujas defesas naturais são influenciadas por um ambiente saudável ou não.

Embora todas as categorias tratem de assuntos distintos, todos eles são correlacionados a um único item em destaque, que são as infecções hospitalares e as diversas formas que Nightingale contribuiu para que pudessem ser evitadas.Desde então, a enfermagem tem assumido as funções de prevenção e controle da contaminação do ambiente hospitalar.

A discussão dos resultados foi subdividida nas principais categorias de contribuição de Nightingale (Quadro 2), conforme relato nos trabalhos selecionados.

\subsection{Contribuições de Florence Nightingale ao meio ambiente}

Na temática Ambiente, o estudo de Frello e Carraro (2013) relata como Nightingale tornou claras as relações entre o ser humano, o ambiente e a natureza como um meio de aprendizagem para crescimento profissional por meio da conexão entre saúde, cuidado e cura. Ressalta que antes da atuação de Florence os hospitais eram como casas de repouso, onde a morte coexistia desveladamente com a vida; insetos e roedores disputavam alimento com os pacientes; mortos e vivos permaneciam no mesmo leito.

Já no trabalho de Ferreira (2012) é apresentada a informação de que Nightingale instituiu o modelo ambiental de saúde que ainda hoje é preconizado pelo Mi- 
nistério da Saúde (MS). Em Haddad e Santos (2011) as autoras sustentam a importância de uma das principais teorias (Teoria Ambientalista) de enfermagem e sua correlação com o ensino da prática da profissão.

E Gill (2005) nos revela que em 1860, Nightingale enfatizou a importância da higiene, limpeza e padrões de cuidados e sanitarismo, a fim de evitar as infecções hospitalares, porém mesmo com todos esses anos ainda encontram-se infecções em hospitais e outros serviços de saúde, no qual permeiam uma grande preocupação para os serviços de saúde.

Os relatos apresentados nos trabalhos de Frello e Carraro (2013), Ferreira (2012), Haddad e Santos (2011) e Gill (2005) apontam a importância da teoria ambientalista e como por meio dela, tem se evitado milhares de mortes por infecções hospitalares e contaminações devido à falta de um ambiente adequado e a falta de higiene básica, que nos leva às preocupações higiênicas "ar puro, água pura, drenagem eficiente, limpeza e luz", cinco pontos essenciais na observação de um ambiente saudável.

Nightingale com a teoria dos germes tinha deduzido que a limpeza, o ar fresco, os aspectos sanitários, o conforto e a socialização eram necessários para a cura. Porém, mesmo com todos esses anos, ainda se encontram infecções em hospitais e outros serviços de saúde, no qual permeiam uma grande preocupação para a sociedade, dentre eles as bactérias multirresistentes que poderiam ser evitadas com o uso de técnicas adequadas de enfermagem, no qual foram, previamente, instituídas por Florence Nightingale há mais de 150 anos (OGUISSO, 2005).

\subsection{Contribuições de Florence Nightingale à epide- miologia}

Essa categoria aborda a inovação da inclusão do caráter epidemiológico. Observa-se, segundo Ellis (2010), que a convicção do seu trabalho levou a idealizadora a se tornar em 1858 a primeira mulher a ser eleita pela Sociedade de Estatística Real, e membra honorária da Associação de Estatística Americana em 1874, publicando ao longo de sua carreira um vasto conjunto de trabalhos, utilizados até hoje.

No primeiro artigo, C. Junior (2013) pode evidenciar que Nightingale promoveu mudanças marcantes com a diminuição da propagação de organismos infecciosos, juntamente às análises epidemiológicas dos motivos das mortes, que proporcionaram evidências científicas da enfermagem que refletiram um aspecto diferenciado do cuidado/atenção com qualidade.

Moraes (2012) nos revela que vários estudiosos afirmam que Nightingale é considerada uma das precursoras da epidemiologia hospitalar por meio da sua introdução a interpretação estáticas de dados coletados.

Já o autor Carrasco (2011) constata que, mesmo em resistência por parte dos médicos e militares, Nightingale conseguiu organizar, e avaliar, estatisticamente, o impacto da atenção sobre os soldados doentes durante a guerra diminuindo, significativamente, a taxa de mortalidade de $40 \%$ para $2 \%$ por doenças infecciosas, demonstrando por meio de cálculos estatísticos a relação entre saneamento e a presença da doença.

Felix (2013) destaca a atuação de Nightingale a desenvolver a prática com suporte epidemiológico para a prevenção e controle de doenças infecciosas e infecções hospitalares, numa época pré-bacteriológica, a qual ainda repercute nos dias atuais. Sendo considerada como a pioneira na aplicação da estatística e da epidemiologia, conseguiu, por meio de simples medidas, controlar a infecção e consequentemente diminuir a morbimortalidade.

Winkelstein (2009) destaca que, na ilustre galeria dos que desenvolveram conhecimentos e métodos que contribuíram para controle da infecção hospitalar estão Florence Nightingale, Joseph Lister, Louis Pasteur e William Halstedt. Figueiredo (2008) relata que Florence Nightingale desenvolveu métodos de coletas de dados que objetivaram a melhoria da qualidade do atendimento prestado aos feridos. Nightingale utilizou-se de indicadores (por exemplo, taxa de mortalidade) para provar que, por meio do controle sanitário, as mortes poderiam diminuir.

Em toda essa categoria apresentada pelos autores supracitados, é possível afirmar que Nightingale foi inovadora ao coletar, tabular, interpretar e ilustrar as estatísticas descritivas. Nesse aspecto de sua carreira, inventou o diagrama área-polar para facilitar o entendimento dos dados referentes às taxas de mortalidade e vinculando com as suas relações com as condições de vida dos pacientes.

Desse modo, ao valorizar a coleta de dados e do uso rigoroso das estatísticas, Nightingaletornou-se pioneira na utilização de métodos de representação visual de informação com o gráfico setorial (conhecido como gráfico tipo "pizza") para apresentação de estatísticas. Sua ideia mostrou que seria possível unir os fenômenos sociais com 
análise matemática, usando a estatística, e mostrando, efetivamente, a todos, graficamente, a necessidade imediata da reforma sanitária por meio de dados epidemiológicos, associando sua formação em matemática e em cuidados e organização de serviços de saúde e na sua melhora significativa na prevenção e controle de doenças.

\subsection{Contribuições de Florence Nightingale no cen- tro cirúrgico}

Nessa categoria pode-se identificar, por meio do autor Matarazzo (2013), que Nightingale escreveu a importância a respeito das vantagens da recuperação e dos efeitos imediatos da cirurgia em uma unidade separada do hospital, observando seu cuidado de evitar infecções cruzadas vindas de outros pacientes enfermos e um cuidado melhor assistido. Reforçando essa ideia, Rossaneis (2013) nos mostra que as contribuições da enfermeira inglesa tornaram possível neutralizar a dor e proteger contra as infecções contraídas no ato cirúrgico.

Já Fonseca (2008) ressalta a importância da enfermagem em centro cirúrgico e como era sua responsabilidade manter um ambiente seguro, confortável e limpo para a realização da operação. Essa importância foi salientada por Florence Nightingale que preconizou as boas condições ambientais como fator importante para o restabelecimento da saúde.

E por fim, Andrade (2002) refere que nos escritos de Nightingale, resgata a importância na prevenção de infecções em campo cirúrgico, através de seus suportes epidemiológicos que permeava no dia-a-dia da assistência de enfermagem, justamente naquela época que estavam ocorrendo conflitos e enfrentamentos de concepções epidemiológicas.

Consistia, fundamentalmente, que a mesma aplicava as medidas de prevenção da proliferação e transmissão de microrganismos. Além disto, ela se preocupava em conhecer as doenças e medidas de prevenção de infecções. E pode-se dizer que Florence Nightingale e John Snow atuaram juntos na epidemia de cólera em Londres. Imersa nesta realidade Nightingale lançava propostas práticas e objetivas para a atuação da Enfermagem e as colocava em ação.

As observações relevantes mencionadas pelos autores Matarazzo (2013); Rossaneis (2013); Fonseca (2008); Andrade (2002) propiciou destacar os modos de ser e de atuar dos enfermeiros no cenário de tratamento cirúrgico, bem como a importância de dispor de uma enfermeira como agente modificador da realidade social e observar a relevância em pequenos detalhes, que previnem a propagação de agentes infecciosos, como por exemplo, o cuidado de uma sala de recuperação isolada dos demais pacientes enfermos, em que, naquela época, havia falhas nessa atenção, sendo ricamente introduzidos por Nightingale.

Considerando-se o elevado número de procedimentos realizados e a complexidade da unidade, o enfermeiro tem um papel fundamental que exige, além do conhecimento científico, responsabilidade, habilidade técnica e estabilidade emocional. Para organizar o processo de cuidar, coordenar e controlar o trabalho da equipe de enfermagem, desta forma mantendo o centro cirúrgico adequado ao paciente, livre de possíveis infecções pós-cirúrgicas.

\subsection{Contribuições de Florence Nightingale as pesso- as enfermas}

Essa etapa foi composta por quatro (04) trabalhos com abordagens muito parecidas onde foi possível verificar que ficou claro a importância e a devoção que Nightingale ao próximo e onde em toda a história a mesma providenciou formas incondicionais de bem-estar e qualidade de vida (Q.V) ao ser humano, observando a importância de realizar a triagem de um paciente, os separando de acordo com as suas necessidades, humanização e individualização, reconhecendo que em todas as ações tinham uma única finalidade de reduzir as taxas de mortalidade hospitalar, contraídas por falta de administração e cuidado ao paciente.

No primeiro estudo, conforme Valle (2013) foi possível observar que Nightingale teve sua significativa importância histórica com a reorganização dos hospitais e a implantação de medidas sanitárias, práticas básicas de higiene, isolamento dos enfermos, atendimento individual, e a redução de leitos no mesmo ambiente, medidas essas que colaboraram para a redução das taxas de mortalidade hospitalar daquela época.

Scarparo (2012) afirma que Nightingale colocou em atuação o que considerava serem as práticas ideais para a enfermagem, preocupando-se com a alimentação adequada, a limpeza, a ventilação do ambiente, a higiene, a separação entre os doentes e os feridos. Já Costa (2011) nos diz que a Teoria Ambientalista sustentada por Nightingale vai além do ambiente físico ao preocupar-se com a qualidade do cuidado realizado ao ser humano, 
apontando suas necessidades como distrações a partir de estímulos visuais, visitas agradáveis, contatos com a natureza, trabalhos manuais, dentre outros. Fortalecendo a imagem de que a enfermagem ao cuidar do ser humano, precisava auxiliá-lo na busca das melhores condições possíveis, a fim de que a natureza realizasse um processo restaurador ao paciente.

No último estudo de Padilha (1999), pode-se destacar que Nightingale influenciou, diretamente, em sua passagem em todos os locais em que se executava o cuidado de enfermagem leigo e fundamentados nos conceitos religiosos de caridade, amor ao próximo, doação, humildade e também pelos preceitos de valorização do ambiente adequado para o cuidado, divisão social do trabalho em enfermagem e autoridade sobre o cuidado a ser prestado ao paciente, os mostrando o caráter científico conquistado pela mesma.

As lições retiradas dos escritos de Nightingale nessa categoria mencionadas pelos autores Valle (2013); Scarparo (2012); Costa (2011); Padilha (1999), em relação aos cuidados com o paciente, Nightingale já nos dizia que estes deveriam ser tratados de maneira integral, ou seja, não somente a doença, mas em seu todo, observando-se que, na enfermagem moderna, ainda permeiam os ensinamentos de Nightingale, por meio da medicina psicossomática, conhecida na atualidade como uma ciência interdisciplinar, que estuda vários fatores sociais e psicológicos do indivíduo, considerados por alguns autores uma inovação, porém este já fazia parte dos seus cuidados. Nightingale já se atentava a preocupação de observar o estado mental do doente e os impactos causados em sua recuperação, tudo isso correlacionado ao como um todo, mantendo um ambiente físico positivo, livre de estresse e os cuidados mais minuciosos na prevenção de contaminações cruzadas. Para isso constatou-se que era necessário uma assistência de enfermagem adequada, sucedendo triagem de pacientes, os separando conforme o nível de gravidade, e desta forma minimizando os riscos de infecções hospitalares e causando menos ansiedade ao paciente.

\subsection{Contribuições de Florence Nightingale à Política}

A política é uma das categorias extremamente relevantes neste estudo, pois ainda hoje é essencial na evolução da história da enfermagem e, em particular, na gestão em enfermagem. Nightingale foi uma mulher idealizadora que honrou a enfermagem ao enaltecer um perfil de vocação, bondade, dedicação, caráter, obediência às hierarquias e determinação perante os subordinados, onde nos revelou uma mulher com grande habilidade de trabalho, de convicção, de liderança e de gestão, nos deixando um ideal a ser servido.

No discurso de Fernandes (2014) é assegurado que Nightingale permitiu a implantação na enfermagem, da organização dos hospitais, considerando todos os detalhes, sendo eles os custos, a economia, a divisão do trabalho e a supervisão do local, introduzindo com tudo isso a administração hospitalar, mudando enfim a realidade dos hospitais.

Segundo Frello (2013) descreve a influência de Nightingale em diversas áreas além da enfermagem, a exemplo da estatística, administração em saúde, saúde pública, fisioterapia e espiritualidade. Onde tornou claras as relações entre o ser humano, o ambiente e a natureza como um meio de aprendizagem para crescimento profissional por meio da conexão entre saúde, cuidado e cura.

Já o autor Jackson (2014) ressalta que o legado de Nightingale não só continua, mas nunca foi tão importante. Sua influência com os enfermeiros da atualidade e sobre a reforma social e de saúde, incluindo saneamento, higiene, design hospitalar e as estatísticas que muitas vezes não é totalmente apreciado. Seu foco foi à priorização de higiene. Ela descreveu os 05 componentes essenciais para ótima cura: ar puro, água pura, drenagem eficiente, limpeza e luz.

De acordo com Jardim (2011) aprendemos que Nightingale colocou a enfermagem no patamar de ciência ao utilizar os vários recursos descritos como forma de reduzir os efeitos negativos e de contaminação no meio hospitalar, sendo importante registrar que a enfermagem assume as funções de prevenção e controle da contaminação do ambiente hospitalar.

Por seu trabalho de Nightingale, em que, até então, o cenário hospitalar era sinal de morte e decadência, logo após as suas lutas constantes nas políticas de saúde, os hospitais passaram a ver a saúde como o maior bem produzido, com uma melhora significativa na (Q.V).

Conclui-se que as narrativas dos autores Fernandes (2014); Frello (2013); Jackson (2014); Jardim (2011) que Nightingale nos ensinou as várias formas de administração e sua atuação na política, em não medir esforços para obter um elevado crescimento no desenvolvimento de uma prática assistencial de enfermagem com excelência, reforçando a preocupação de relatar as descrições 
detalhadas das técnicas e procedimentos, visando o controle de qualidade o melhor possível e em diversas áreas de atuação e apresentar a enfermagem como uma profissão reconhecida perante a sociedade. E continuar com o seu legado atuando na política a favor dos direitos da enfermagem, levando a profissão o respeito, dignidade e valores merecidos.

Observa-se, também, que o padrão de conhecimento sociopolítico contribui para que o enfermeiro tenha uma visão abrangente que evidencia a responsabilidade e o compromisso como agente de mudanças sociais, organizacionais e políticos, dedicando na renovação, inovação e no desenvolvimento sustentável do processo de trabalho da enfermagem a favor da saúde coletiva e individual.

\subsection{Contribuições de Florence Nightingale ao sani- tarismo}

Nessa $6^{\circ}$ e última categoria, o contexto descrito é o sanitarismo um dos objetivos principais deste trabalho, onde tendo conhecimento da cadeia epidemiológica que está associada à transmissão das infecções, incluindo elos importantes entre o microrganismo, o reservatório e o hospedeiro. Nightingale assumiu um papel importantíssimo na prevenção das infecções, por tornar as demais pessoas conscientes da importância de uma vigilância sanitária, que só intervindo podemos tomar as atitudes adequadas, em que, ainda, hoje temos grandes preocupações referentes a esta categoria.

De acordo com Magnello (2006), Nightingale utilizava a informação estatística para educar, aludir e impulsionar o governo e a sociedade, que vissem a necessidade de uma mudança. Ao longo de sua incrível perseverança, conseguiu persuadir vários oficiais do governo que as taxas de mortalidade poderiam ser reduzidas no exército e na população civil, com a introdução de medidas de higiene e saneamento básico.

Os fatos observados impulsionam Nightingale a solicitar uma Comissão Sanitária ao governo Britânico, que após a intervenção da referida comissão, se dedicou à reforma do saneamento do exército e aos seus hospitais. Se tornando a primeira Sanitarista, fazendo com que as taxas de mortalidade caíssem abruptamente estabelecendo um dos primeiros modelos de melhoria da (Q.V). E como as práticas relacionadas à infecção, iniciadas instintivamente por Nightingale, ao longo dos anos foram significativas, se tornaram científicas e até os dias atuais ainda são aplicáveis no cuidado ao paciente (BARBAN, 2013).

Nesse contexto,sistematizar, aquilo que vem sendo abordado em relação ao tema, como o conceito de infecção hospitalar é algo de grande importância para contribuir na construção de conhecimentos correlacionados a uma teoria, que nos mostra como é relevante a enfermagem e como vem sofrendo nos últimos anos. A prevenção das infecções tem sofrido uma evolução significativa, contudo, apesar dos grandes avanços tecnológicos a que assistimos, mesmo assim, verificamos um aumento do número de infecções (PADILHA, 2005).

Entretanto, a prevenção no controle da infecção tem um papel óbvio e importante na garantia de que os pacientes recebam cuidados de alta qualidade. As infecções adquiridas na sequência dos cuidados de saúde provocam morbidade e mortalidade consideráveis, levando ao aumento de custos, além dos excessivos gastos que incluem a assistência especializada, terapêutica antibiótica e outros fármacos, exames complementares de diagnóstico, tratamentos, graças aos custos inerentes relacionados ao prolongamento do internamento no hospital, com repercussões familiares e sociais (HORTON, 2002).

A prevenção, sob todos esses aspectos, assume o papel preeminente do controle da infecção, evento para o qual os enfermeiros têm responsabilidade na procura de um ambiente hospitalar biologicamente seguro e confortável, sendo este um cenário elementar apresentado por Nightingale (PEREIRA et al., 2005).

Nos seis (06) artigos, foi possível evidenciar o papel fundamental de Nightingale no controle de infecções, sendo possível visualizar que Nightingale influenciou, notadamente, na reforma sanitária da Índia, na Inglaterra, nas melhores práticas de saúde do povo indígena da Austrália, na melhora das condições de higiene, dos inúmeros casos de cólera e tifo. Em Scutari (Turquia), onde por 21 meses, organizou, limpou, humanizou e conseguiu reduzir de $42 \%$ para $2 \%$ a mortalidade entre os feridos de guerra (FRELLO; CARRARO, 2013).

\section{Considerações finais}

Ao desenvolver este trabalho, foi possível observar a importância de aprofundar na história da enfermagem e como vem ocasionando as mudanças no seu desenvolvimento ao longo dos anos, buscando as principais fontes sobre a origem e o desenvolvimento da saúde pública a 
partir da dedicação envolvendo a reforma da saúde hospitalar de acordo com Nightingale. A visão precursora da mesma é confirmada por meio de sua Teoria Ambientalista onde foi possível verificar o quanto essa teoria ainda causa um imenso impacto nos dias atuais. O escopo de sua influência na enfermagem moderna alcança temas como reforma sanitária, higiene, design dos hospitais, estatística e epidemiologia.

É de extrema importância observar que nem todos os estudos analisados tratam, diretamente de Nightingale ou da enfermagem, mas citam os trabalhos dela e suas contribuições como forma de merecimento e valorização dos seus atos perante o controle das infecções hospitalares, reforçando esse reconhecimento.

Em todo tempo, a enfermeira britânica introduziu vários formas de combater tudo aquilo que causasse danos ao paciente, fazendo com que se tornasse um dos pioneiros em uma visão epidemiológica e sanitarista, mesmo em uma era pré-bacteriológica. Onde introduziu um sistema de coleta de dados estatísticos, a fim de fornecer bases científicas para uma melhora na qualidade do atendimento e da administração hospitalar, intensificando a qualidade e a administração em saúde, levando isso a todas as enfermeiras que fossem treinadas por ela e em todo o mundo.

Por intermédio da observação dos trabalhos de Nightingale, foi possível desenvolver técnicas de prevenção a infecções hospitalares, por meio de dados coletados, levando a realizar a triagem de pacientes, divisão de alas e isolamentos, o que nos mostrou a importância de resguardamos os pacientes em situações de pós-cirúrgico e a importância de um ambiente adequado. Além disso, foi possível destacar a influência desta no design interior de um hospital adequado. Dessa forma, a enfermeira pioneira conseguiu mostrar e introduzir inúmeras mudanças mesmo numa época onde o trabalho da mulher era menos valorizado.

Porém, mesmo com todos esses estudos e ensinamentos de Nightingale, ainda hoje, com todos esses avanços tecnológicos, é percebido que, ainda, há o aumento das taxas de infecção hospitalar, no qual poderá ser um sinal de que a melhora da (Q.V) nem sempre é a verdade. É preciso usar bom senso, ao lado da tecnologia, na construção de melhores tempos.

Constatando que um dos elementos fundamentais do controle das infecções é o Enfermeiro, visto que esse profissional de saúde desempenha um papel fundamental na investigação e na vigilância epidemiológica, na formação para a prevenção e controle da infecção e, principalmente, na gestão das práticas, especialmente as que se relacionam com a segurança dos cuidados de enfermagem.

Destaca-se que a situação atual da prática do enfermeiro na sociedade brasileira de fato obteve avanços, mas também conflitos no que se refere às práticas e teóricas,mostrando o quanto é primordial uma revisão das concepções teórico-metodológicas no processo do cuidar em enfermagem e saúde e nada melhor do que retornarmos ao princípio, ou nos basearmos nos fatos e fenômenos históricos, para que não venhamos a cometer erros já cometidos.

\section{Referências}

AGÊNCIA NACIONAL DE VIGILÂNCIA SANITÁRIA. Critérios Diagnósticos de Infecção Relacionada à Assistência à Saúde. Brasília: ANVISA, 2013.

ANDRADE, G. M. Infecção hospitalar: mitos e verdades, velhos hábitos, novas atitudes. Brasília Médica, Brasília, v. 39, n. 4 , p. 57-59, fev. 2002.

BARBAN, A. Análise da mobilização e resultados do transplante de células-tronco hematopoiéticas autogênico (TCTHa) com alta hospitalar precoce nos portadores de doenças hematológicas. 2013. 110 f. Dissertação (Mestrado em Processos Imunes e Infecciosos) - Faculdade de Medicina, Universidade de São Paulo, São Paulo, 2013.

BRASIL. Ministério da Saúde. Portaria n ${ }^{\circ} 2616$ de 12 de maio de 1998. Regulamenta as ações de controle de infecção hospitalar no país. 1998. Disponível em: <http:/bvsms.saude.gov.br/bvs/saudelegis/gm/1998/ prt2616_12_05_1998.html>. Acesso em: 12 nov. 2015.

CARRARO, T. E. Resgatando Florence Nightingale: a trajetória da enfermagem junto ao ser humano e sua família na prevenção de infecções. Revista Brasileira Enfermagem, Brasília, v. 48, n. 4, p. 448-449, dez. 1995. doi: 10.1590/S0034-71671995000400014.

CARRASCO, E. R. N. Comprensión de la enfermería desde la perspectiva histórica de Florencia Nightingale. Ciencia y Enfermeria, Concepción, v. 17, n. 1, p. 1118, jun. 2011. doi: 10.4067/S0717-95532011000100002. 
COSTA, G. A. Aplicação do Pediatric Risk of Mortality escore (PRISM) e determinação dos fatores de prognóstico para óbito em uma unidade de terapia intensiva pediátrica terciária. 2011. 108 f. Dissertação (Mestrado em Pediatria) - Faculdade de Medicina, Universidade de São Paulo, São Paulo, 2011.

ELLIS, H. Florence Nightingale: nurse and public health pioneer. British Journal of Hospital Medicine, London, v. 71, n. 1, p. 51-52, jan. 2010. doi: 10.12968/ hmed.2010.71.1.45975.

FELIX, A. M. S. Fatores individuais, laborais e organizacionais à adesão às precauções-padrão de profissionais de enfermagem em uma instituição privada. Journal of Infection Control, Santa Cruz do Sul, v. 2, n. 2, p. 106-111, abr. 2013.

FERNANDES, H. M. L. G. Acreditação hospitalar: a percepção da equipe de enfermagem do centro cirúrgico de um hospital universitário. 2014. 181 f. Dissertação (Mestrado em Enfermagem na Saúde do Adulto) - Escola de Enfermagem, Universidade de São Paulo, São Paulo, 2014.

FERREIRA, C. T. M. Adoção da sistematização de assistência de enfermagem em Unidades de Referência em Hanseníase no município de São Paulo: limites e possibilidades. 2012. 116 f. Dissertação (Mestrado em Cuidado em Saúde) - Escola de Enfermagem, Universidade de São Paulo, São Paulo, 2012.

FIGUEIREDO, A. Gestão do projeto de edifícios hospitalares. 2008. 214 f. Dissertação (Mestrado em Arquitetura, Urbanismo e Tecnologia) - Escola de Engenharia de São Carlos, Universidade de São Paulo, São Carlos, 2008.

FONSECA, R. M. P. Revisão integrativa da pesquisa em enfermagem em centro cirúrgico no Brasil: trinta anos após o SAEP. 2008. 135 f. Dissertação (Mestrado em Enfermagem na Saúde do Adulto) - Escola de Enfermagem, Universidade de São Paulo, São Paulo, 2008.

FRELlO, A. T.; CARRARO, T. E. Contribuições de Florence Nightingale: uma revisão integrativa da literatura. Escola Anna Nery, Rio de Janeiro, v. 17, n. 3, p. 573579, Aug. 2013. doi: 10.1590/S1414-81452013000300024.

GAROFALO, M. E.; FEE, E. Florence Nightingale (1820-
1910): feminism and hospital reform. American Journal of Public Health, New York, v. 100, n. 9, p. 57-58, Sep. 2015. doi: 10.2105/AJPH.2009.188722.

GEORGE, J. B. Teorias de enfermagem: dos fundamentos para à prática profissional. 4. ed. Porto Alegre: Artes Médicas Sul, 2000.

GILL, C. J. Nightingale in Scutari: her legacy reexamined. Clinical Infectious Diseases, Boston, v. 40, n. 12, p. 1799-1805, jun. 2005. doi: 10.1086/430380.

GRAAF, K. R. Florencia Nightingale: enfermeria moderna. Teorias y Modelos de Enfermeria, Barcelona, v. 4, n. 92, p. 35-39, jun. 1989.

HADDAD, V. C. N.; SANTOS, T. C. F. A teoria ambientalista de Florence Nightingale no ensino da escola de enfermagem Anna Nery (1962 - 1968). Escola Anna Nery, Rio de Janeiro, v. 15, n. 4, p. 755-761, dez. 2011. doi: 10.1590/S1414-81452011000400014.

HEARST, N. et al. Pesquisas com dados existentes: análise de dados secundários, estudos suplementares e revisões sistemáticas: delineando a pesquisa clínica. 2. ed. Porto Alegre: Artmed, 2003.

HESELTINE, P. Why don't doctors and nurses wahs their hands? Infection Control \& Hospital Epidemiology, Cambridge, v. 22, n. 4, p. 199-200, jan. 2001. doi: $10.1086 / 501888$.

HORTON, R. Nurses' knowledge of infection control. Nursing Standard, London, v. 7. n. 41. p. 25-29, May. 1993. doi: 10.7748/ns.7.41.25.s36.

JACKSON, C. Infection prevention as "a show": a qualitative study of nurses' infection prevention behaviours. International Journal of Nursing Studies, London, v. 51, n. 3, p. 400-401, mar. 2014. doi: 10.1016/j.ijnurstu.2013.07.002.

JARDIM, J. M. Avaliação das práticas de prevenção e controle da infecção da corrente sanguínea associada ao cateter venoso central de curta permanência por meio de indicadores clínicos. 2011. 175 f. Dissertação (Mestrado em Enfermagem na Saúde do Adulto) - Escola de Enfermagem, University of São Paulo, São Paulo, 2011. 
LOPES JÚNIOR, L. C. Análise do ensino de genética e genômica em cursos de graduação em enfermagem no Brasil. 2013. 129 f. Dissertação (Mestrado em Enfermagem em Saúde Pública) - Escola de Enfermagem de Ribeirão Preto, Universidade de São Paulo, Ribeirão Preto, 2013.

LOPES, A. L. M.; FRACOLLI, L. A. Revisão sistemática de literatura e metassíntese qualitativa: considerações sobre sua aplicação na pesquisa em enfermagem. Texto \& Contexto - Enfermagem, Florianopolis, v. 17, n. 4, p. 771778, dez. 2008. doi: 10.1590/S0104-07072008000400020.

MAGNELLO, M. E. Victorian vital and mathematical statistics. BSHM Bulletin: Journal of the British Society for the History of Mathematics, London, v. 21, n. 3, p. 219229, fev. 2006. doi: 10.1080/17498430600964508.

MATARAZZO, A. K. Z. Composições cromáticas no ambiente hospitalar: estudo de novas abordagens. 2010. 215 f. Dissertação (Mestrado em Tecnologia da Arquitetura) - Faculdade de Arquitetura e Urbanismo, Universidade de São Paulo, São Paulo, 2013.

MORAES, M. K. As contribuições do atendimento educacional em ambiente hospitalar a crianças que realizam tratamento oncológico. 2010. 138 f. Dissertação (Mestrado em Educação) - Faculdade de Educação, Universidade de São Paulo, São Paulo, 2012.

NIGHTINGALE, F. Notas sobre enfermagem: o que é e o que não é. São Paulo: Cortez, 1989.

OGUISSO, T. Florence Nightingale: trajetória histórica e legal da enfermagem. São Paulo: Manole, 2005.

OLALDE, M. G. Escala SERVQUAL: validação para a cultura mexicana e a qualidade do serviço de enfermagem, segundo a percepção de pacientes hospitalizados. 2008. 105 f. Tese (Doutorado em Enfermagem Fundamental) - Escola de Enfermagem de Ribeirão Preto, Universidade de São Paulo, Ribeirão Preto, 2008.

PADILHA, M. I. C. S. A mística do silêncio: a enfermagem na Santa Casa de Misericórdia do Rio de Janeiro no século XIX. Pelotas: UFPel, 1998.

PADILHA, M. I. C. S.; MANCIA, J. R. Florence Nightin-
Brasileira de Enfermagem, Brasília, v. 58, n. 6, p. 723726, dez. 2005. doi: 10.1590/S0034-71672005000600018.

PADILHA, M. I. C. S. As representações da história da enfermagem na prática cotidiana atual. Revista Brasileira de Enfermagem, Brasília, v. 52, n. 3, p. 443-454, set. 1999. doi: 10.1590/S0034-71671999000300014.

PENHA, R. M. A expressão da dimensão espiritual no cuidado de enfermagem em UTI. 2008. 176 f. Dissertação (Mestrado em Enfermagem na Saúde do Adulto) - Escola de Enfermagem, Universidade de São Paulo, São Paulo, 2008.

PEREIRA, M. S. et al. A infecção hospitalar e suas implicações para o cuidar da enfermagem. Texto \& Contexto - Enfermagem, Florianópolis, v. 14, n. 2, p. 250-257, jun. 2005. doi: 10.1590/S0104-07072005000200013.

ROSSANEIS, M. A. Indicadores de qualidade adotados nos serviços de enfermagem de hospitais de ensino do Estado do Paraná, Brasil. 2013. 123 f. Dissertação (Mestrado em Enfermagem Fundamental) - Escola de Enfermagem de Ribeirão Preto, Universidade de São Paulo, Ribeirão Preto, 2013.

SAVAGE, C. Public health and nursing: a natural partnership. International Journal of Environmental Research and Public Health, Basel, v. 6, n. 11, p. 2843-2848, nov. 2009. doi: 10.3390/ijerph6112843.

SCARPARO, A. F. Perspectivas do gerenciamento de enfermagem hospitalar. 2012. 151 f. Tese (Doutorado em Enfermagem Fundamental) - Escola de Enfermagem de Ribeirão Preto, Universidade de São Paulo, Ribeirão Preto, 2012.

VALLE, A. R. M. C. Competências do enfermeiro para ações preventivas na atenção domiciliar com ênfase nos riscos de infecção. 2013. 262 f. Tese (Doutorado em Enfermagem Fundamental) - Escola de Enfermagem de Ribeirão Preto, Universidade de São Paulo, Ribeirão Preto, 2013.

WINKELSTEIN, W. J. Florence Nightingale: founder of modern nursing and hospital epidemiology. Epidemiology, Hargerstown, v. 20, n. 2, p. 311, mar. 2009. doi: 10.1097/EDE.0b013e3181935ad6. 